\title{
Correction to: Do pain, anxiety and depression influence quality of life for people with amyotrophic lateral sclerosis/motor neuron disease? A national study reconciling previous conflicting literature
}

\author{
Rhiannon Edge ${ }^{1}\left[\right.$ - Roger Mills ${ }^{2} \cdot$ Alan Tennant ${ }^{4} \cdot$ Peter J. Diggle ${ }^{1} \cdot$ Carolyn A. Young ${ }^{2,3}$ on behalf of the TONiC study \\ group
}

Published online: 28 January 2020

(c) The Author(s) 2020

\section{Correction to: Journal of Neurology https://doi.org/10.1007/s00415-019-09615-3}

The original version of this article unfortunately contained a mistake. C Oliver Hanemann's was incorrect in the acknowledgements section of this paper.

The correct name should be C. Oliver Hanemann. The correct acknowledgements section should read as:

Acknowledgements The authors would like to thank the participants of the Trajectories of Outcome in Neurological Conditions (TONiC) Study for contributing their data for research.

\section{TONiC Study Group Membership}

Ammar Al-Chalabi ${ }^{1}$, Timothy L Williams ${ }^{2}$, David J Dick $^{3}$, Kevin Talbot ${ }^{4}$, Georgina Burke ${ }^{5}$, Tahir Majeed ${ }^{6}$, John Ealing ${ }^{7}$, Christopher J. McDermott ${ }^{8}$, Ashwin Pinto ${ }^{9}$, Carolyn A. Young ${ }^{10}$, Siddharthan Chandran ${ }^{11}$, Jannette Walsh ${ }^{12}$, C. Oliver Hanemann ${ }^{13}$, Timothy Harrower ${ }^{14}$

The original article can be found online at https://doi.org/10.1007/ s00415-019-09615-3.

Rhiannon Edge

r.edge@lancaster.ac.uk

1 Lancaster Medical School, Lancaster University, B38 Furness Building, Bailrigg, Lancaster, UK LA1 4YW

2 Walton Centre NHS Trust, Lower Lane, Liverpool L9 7LJ, UK

3 University of Liverpool, Liverpool L69 3BX, UK

4 Emeritus Professor, Leeds Institute of Rheumatic and Musculoskeletal Medicine, University of Leeds, Leeds, UK

\section{Affiliations}

1. King's College London, London, UK

2. Royal Victoria Infirmary, Newcastle upon Tyne, UK

3. Norfolk and Norwich University Hospital, UK

4. University of Oxford, Oxford, UK

5. Queen Alexandra Hospital, Portsmouth, UK

6. Lancashire Teaching Hospitals, Preston, UK

7. Salford Royal Foundation Trust, Manchester, UK

8. University of Sheffield, Sheffield, UK

9. Wessex Neurological Centre, Southampton, UK

10. Walton Centre NHS Foundation Trust, Liverpool, UK

11. Royal Infirmary of Edinburgh, Edinburgh, UK

12. Staffordshire and Stoke on Trent Partnership NHS

Trust, Newcastle-under-Lyme, UK

13. University of Plymouth, Drake Circus, Plymouth, UK 14. Northern Devon Healthcare NHS Trust, Devon, UK Email addresses

1. ammar.al-chalabi@kcl.ac.uk

2.Tim.Williams@nuth.nhs.uk

3. david.dick@nnuh.nhs.uk

4. kevin.talbot@ndcn.ox.ac.uk

5. georgina.burke@ porthosp.nhs.uk

6. Tahir.Majeed@lthtr.nhs.uk

7. john.ealing@srft.nhs.uk

8. c.j.mcdermott@sheffield.ac.uk

9. Ashwin.Pinto@uhs.nhs.uk

10. carolyn.young@thewaltoncentre.nhs.uk 
11. siddharthan.chandran@ed.ac.uk

12. Jannette.Walsh@ssotp.nhs.uk

13. oliver.hanemann@plymouth.ac.uk

14. timothy.harrower@nhs.net

The members of the TONiC Study group contributed to the development of a larger programme of work of which this study is a part. The members have co-ordinated data collection as part of the development of the TONiC study. The TONiC study group's contribution should be acknowledged as a corporate author.

Open Access This article is licensed under a Creative Commons Attribution 4.0 International License, which permits use, sharing, adaptation, distribution and reproduction in any medium or format, as long as you give appropriate credit to the original author(s) and the source, provide a link to the Creative Commons licence, and indicate if changes were made. The images or other third party material in this article are included in the article's Creative Commons licence, unless indicated otherwise in a credit line to the material. If material is not included in the article's Creative Commons licence and your intended use is not permitted by statutory regulation or exceeds the permitted use, you will need to obtain permission directly from the copyright holder. To view a copy of this licence, visit http://creativecommons .org/licenses/by/4.0/. 